\title{
The effects of body image, commitment, and attitude on behavior after purchase of Pilates consumers
}

\author{
Su Yeon Roh* \\ Department of Exercise Rehabilitation and Welfare, College of Health Science, Gachon University, Incheon, Korea
}

In order to investigate the effects of body image, commitment, and attitude on behavior after purchase of the Pilates consumers, this study sampled adults who were participating in the exercise at a Pilates center. By using the convenience sampling method, the data of 253 persons were analyzed. In relation to the appearance orientation and physical satisfaction, which are subfactors of the body image of a Pilates consumer, commitment and appearance evaluation have significant effects on attitudes, such as additional effort and satisfaction. Trust, appearance evaluation, and body satisfaction have significant effects on recommendation, appearance orientation, and appearance evaluation of postpurchase behavior. Body satisfaction has a significant effect on the duration of the exercise after purchase. Commitment of Pilates consumers has a significant effect on attitudes, such as additional effort and satisfaction, while trust and commitment have significant effects on the recommendation to others after purchase and the duration of the exercise. Therefore, a program based on the basic principles of Pilates that can increase the interest and demand of the customers, and a systematic exercising method for improving the health of the customers are deemed necessary. These will help customers in having a positive attitude by creating a positive body image and increasing their engagement. In addition, these can convey positive images about Pilates and encourage customers to spend time on working out regularly by fulfilling their value and increasing their quality of life.

Keywords: Pilates, Body image, Commitment

\section{INTRODUCTION}

It is estimated that around 3,000 to 5,000 Pilates educational institutions are up and running as of 2017 , with the number of Pilates licenses registered in private qualification information services amounting to 204 in September 2017 as compared to only 2 in 2011. The market is growing at a whopping 100 times (Prime Economy, 2017).

Pilates helps in increasing body flexibility, correcting postures, and recovering and enhancing physical strength, which are combined together to foster public interest for Pilates education. Beautiful appearance and slender body shape are envied by both young and old regardless of their gender due to the changing social atmosphere, and people are paying constant attention to their perceived body image by internalizing their ideal physical beauty prompted by the shifting social atmosphere.
'Perceived body image' is formed by a combination of opinions, beliefs, values, goals, personality, and other people's opinions. In addition, it is influenced by socio-cultural effects (Wassner, 1982). It is a condensed concept of the human body that individuals have come to possess as they are forming their identity over the course of going through diverse social experiences, as well as their emotions and attitudes associated with a subjective evaluation of their body (Park and Sung, 2011). A positive view of their perceived body image can lead to positive performance and improve their commitment to performance (Kim et al., 2013). An and Jeon (2014) also showed that the assessment of their external and internal selves obtained from perceived body image can control their satisfaction or dissatisfaction when dancing, while a positively perceived body image can enhance satisfaction. As the perceived body image changes or the attractiveness and self-confidence of an individual increases, trust, which is also an element of attitude,
${ }^{\star}$ Corresponding author: Su Yeon Roh (iD https://orcid.org/0000-0001-5573-5870 Department of Exercise Rehabilitation and Welfare, College of Health Science, Gachon University, 191 Hambangmoe-ro, Yeonsu-gu, Incheon, Incheon 21936, Korea

Tel: +82-32-820-4254, Fax:+82-32-820-4449, E-mail: rsypilates@naver.com Received: September 3, 2018 / Accepted: October 17, 2018
This is an Open Access article distributed under the terms of the Creative Commons Attribution Non-Commercial License (http://creativecommons.org/licenses/by-nc/4.0/) which permits unrestricted non-commercial use, distribution, and reproduction in any medium, provided the original work is properly cited. 
increases as well, thereby indicating that perceived body image and attitude are closely related with each other.

In addition, regular physical activity, such as individual participation and regular performance in sports activities, has a positive effect on the 'continue with exercise' variable (Sonstroem and Morgan, 1989). 'Perceived body image' has also been found to have a positive effect on the will to continue dancing in the 'behavior after purchase' variable, as well as on the 'recommend to others' variable.

'Exercise commitment' has also been shown to increase not only a person's pleasure and sense of achievement, which are attitudes that individuals acquire while exercising, but also exercise satisfaction, which is a positive emotional state that is related to happiness, self-esteem, and reward (Song and Lee, 2015). It has been proven that 'Exercise commitment' is correlated with 'Additional effort' for improving individual ability and trust (Decotiis and Summers, 1987). Furthermore, it also positively affects the 'behavior after purchase', including the 'continue with exercise' and 'recommend to others' variables (Lee, 2014), thereby suggesting that as the sports club members are more committed to the sport they are participating in, they are more likely to recommend to others, such as word of mouth, in order to provide their own assessment to others.

As such, various studies have proven that 'perceived body image' is related to 'exercise commitment,' 'attitude,' and 'behavior after purchase,' and that 'exercise commitment' is again related to 'attitude' and 'behavior after purchase.' The Pilates market is growing and expanding rapidly since it is effective in improving 'perceived body image' as it requires mental concentration, moderated flexibility, and mental and physical integration, and it improves body balance by correcting bad postures, strengthening the muscles, and improving the flexibility of the body (Prime Economy, 2017). However, studies on Pilates have not yet been performed sufficiently.

For this reason, the emphasis on physical beauty has helped change an individual's value on beauty in the modern society. Accordingly, the author will conduct a research on the relationship between 'perceived body image' and 'exercise commitment,' as well as the relationship between the formation of 'attitude' and 'behavior after purchase' ('continue with exercise' and 'recommend to others') by surveying the club members of Pilates, which emphasizes efficacy as an activity for acquiring both physical health and psychological wellness (Roh, 2016). This way, Pilates would be able to develop a positive attitude that can increase an individual's commitment to exercise, meet their own values, improve the quality of their daily life, and propose measures for fostering continued exercise. In this regard, the detailed purposes of this study are shown below:

(a) The perceived body image of the Pilates consumers will affect their commitment to exercise.

(b) The perceived body image of the Pilates consumers will affect their attitude.

(c) The perceived body image of the Pilates consumers will affect their behavior after purchase.

(d) The commitment of the Pilates consumers will affect their attitude.

(e) The commitment of the Pilates consumers will affect their behavior after purchase.

\section{MATERIALS AND METHODS}

\section{Research subjects}

For this study, 300 people were selected by using the convenience sampling method from a population that was set as consumers exercising at Pilates centers scattered across the nation in 2016. The data of 253 respondents were used finally after removing the questionnaires that were not answered sufficiently. Table 1 shows the general characteristics of the subjects that were surveyed.

\section{Research tool}

In this study, questionnaires were used to identify the effects of perceived body image, commitment to exercise, attitude, and behavior after purchase of Pilates consumers. The questions were made up of 5-point Likert-type scale questions, while the varimax method, which is a $90^{\circ}$ rotation of the principal component analysis method, was applied and repositioned according to the size of the factor loading value for the convenience of analysis in order to test its validity. Table 2 shows the variables classified by survey area.

\section{Questions on 'perceived body image'}

The survey questions were based on the Multidimensional Body-Self Relation Questionnaire of Cash and Pruzinsky (1990), which are multidimensional questions on the body and self that were modified from the body-self relation questionnaire. The factor analysis results show that the cumulative dispersion (explanatory power) of the factor analysis on 'perceived body image' was $72.80 \%$, as shown in Table 3 .

The survey questions consisted of a total of 11 items ( 4 items for 1st factor: appearance oriented; 4 items for 2nd factor: appear- 
Table 1. General characteristics of the survey subjects

\begin{tabular}{|c|c|}
\hline Variable & No. of subjects (\%) \\
\hline \multicolumn{2}{|l|}{ Sex } \\
\hline Male & $108(42.7)$ \\
\hline Female & $143(56.5)$ \\
\hline $\mathrm{N} / \mathrm{A}$ & $2(0.8)$ \\
\hline \multicolumn{2}{|l|}{ Age (yr) } \\
\hline$<20$ & $18(7.1)$ \\
\hline $20-29$ & $112(44.3)$ \\
\hline 30-39 & $33(13)$ \\
\hline $40-49$ & $20(7.9)$ \\
\hline$\geq 50$ & $70(27.7)$ \\
\hline \multicolumn{2}{|l|}{ Education } \\
\hline High school graduates & $9(3.5)$ \\
\hline University graduates or currently students & $148(58.5)$ \\
\hline Graduate school graduates and over & 94 (37.2) \\
\hline $\mathrm{N} / \mathrm{A}$ & $2(0.8)$ \\
\hline \multicolumn{2}{|l|}{ Occupation } \\
\hline Student & $102(40.3)$ \\
\hline Professionals & $35(13.8)$ \\
\hline Business owner & $93(36.8)$ \\
\hline Homemaker and others & $22(8.7)$ \\
\hline $\mathrm{N} / \mathrm{A}$ & $1(0.4)$ \\
\hline \multicolumn{2}{|l|}{ Income level } \\
\hline Less than KRW $2 \mathrm{M}$ & $94(37.2)$ \\
\hline KRW $2.01 \mathrm{M}-3 \mathrm{M}$ & $16(6.3)$ \\
\hline KRW $3.01 \mathrm{M}-4 \mathrm{M}$ & $23(9.1)$ \\
\hline KRW $4.01 \mathrm{M}-5 \mathrm{M}$ & $33(13)$ \\
\hline Over KRW $5.01 \mathrm{M}$ & $73(28.9)$ \\
\hline $\mathrm{N} / \mathrm{A}$ & $14(5.5)$ \\
\hline Total & $253(100)$ \\
\hline
\end{tabular}

N/A, not available; KRW, Korean won; M, million.

ance judging; and 3 items for 3 rd factor: satisfied).

Cronbach $\alpha$ value, which is the reliability coefficient used in this study, was 0.832 for 'appearance oriented', 0.884 for 'appearance judging' and 0.802 for 'satisfied'. The overall reliability was 0.884 , thereby suggesting that the questionnaire is reliable enough to be used in the survey.

\section{Questions on 'exercise commitment'}

The questions on 'exercise commitment' were prepared by revising and supplementing the questionnaire used by Kim (2006) to suit the purpose of this study, and they were all based on the questionnaire developed by Kanungo (1982). 'commitment' is a single factor; therefore, factor analysis is not performed and Cronbach $\alpha$ value is 0.877 , which is used as a relatively reliable questionnaire.
Table 2. Indices and contents of the survey questions

\begin{tabular}{lc}
\hline Variable & No. of questions \\
\hline General attributes & 5 \\
Sex & 1 \\
Age & 1 \\
Education & 1 \\
Occupation & 1 \\
Income level & 1 \\
Perceived body image & 12 \\
Appearance oriented & 4 \\
Appearance judging & 4 \\
Satisfied & 3 \\
Exercise commitment, commitment & 4 \\
Attitude & 12 \\
Additional effort & 4 \\
Satisfied & 4 \\
Trust & 4 \\
Behavior after purchase & 4 \\
Recommend to others & 6 \\
Continue with exercise & 4 \\
Total & 28 \\
\hline
\end{tabular}

Table 3. Factor analysis and reliability of 'perceived body image' questions

\begin{tabular}{lcccc}
\hline Question & 1 & \multicolumn{1}{c}{2} & \multicolumn{1}{c}{3} & Shared value \\
\hline Appearance oriented 1 & 0.847 & 0.270 & 0.129 & 0.807 \\
Appearance oriented 2 & 0.773 & 0.050 & 0.390 & 0.752 \\
Appearance oriented 3 & 0.744 & 0.167 & 0.457 & 0.790 \\
Appearance oriented 4 & 0.711 & 0.133 & 0.439 & 0.717 \\
Appearance judging 1 & 0.261 & 0.831 & 0.117 & 0.773 \\
Appearance judging 2 & 0.150 & 0.817 & 0.260 & 0.757 \\
Appearance judging 3 & 0.097 & 0.768 & 0.279 & 0.677 \\
Appearance judging 4 & 0.029 & 0.757 & -0.203 & 0.615 \\
Satisfied 1 & 0.389 & 0.084 & 0.815 & 0.822 \\
Satisfied 2 & 0.235 & 0.151 & 0.763 & 0.660 \\
Satisfied 3 & 0.352 & 0.082 & 0.712 & 0.638 \\
$\quad$ Total & 2.086 & 2.678 & 2.524 & \\
Dispersion (\%) & 25.505 & 24.348 & 22.948 & \\
Accumulation (\%) & 25.505 & 49.853 & 72.801 & \\
Reliability & 0.832 & 0.884 & 0.802 & \\
Total reliability & 0.884 & & & \\
\hline
\end{tabular}

\section{Questions on 'attitude'}

The questions on 'attitude' were prepared to suit the purpose of this study by revising and supplementing the questions on 'additional effort' that were developed by Bass (1985), the questions on 'satisfied' that were developed by Smoll et al. (1978) As illustrated in Table 4, the results of the factor analysis show that the cumulative dispersion (explanatory power) of the factor analysis on 'atti- 
Table 4. Factor analysis and reliability of the questions on 'attitude'

\begin{tabular}{lcccc}
\hline Question & 1 & \multicolumn{1}{c}{2} & \multicolumn{1}{c}{3} & Shared value \\
\hline Additional effort 1 & 0.791 & 0.372 & 0.188 & 0.799 \\
Additional effort 2 & 0.780 & 0.343 & 0.230 & 0.779 \\
Additional effort 3 & 0.751 & 0.312 & 0.344 & 0.779 \\
Additional effort 4 & 0.698 & 0.206 & 0.443 & 0.726 \\
Satisfied 1 & 0.318 & 0.808 & 0.249 & 0.816 \\
Satisfied 2 & 0.336 & 0.765 & 0.332 & 0.807 \\
Satisfied 3 & 0.322 & 0.711 & 0.283 & 0.689 \\
Satisfied 4 & 0.283 & 0.644 & 0.467 & 0.713 \\
Trust 1 & 0.215 & 0.383 & 0.725 & 0.718 \\
Trust 2 & 0.451 & 0.243 & 0.691 & 0.740 \\
Trust 3 & 0.199 & 0.456 & 0.663 & 0.688 \\
Trust 4 & 0.482 & 0.234 & 0.641 & 0.698 \\
$\quad$ Total & 3.205 & 3.022 & 2.727 & \\
Dispersion (\%) & 26.705 & 25.181 & 22.727 & \\
Commutation (\%) & 26.705 & 51.886 & 74.613 & \\
Reliability & 0.899 & 0.892 & 0.852 & \\
Overall reliability & & 0.944 & &
\end{tabular}

tude' was $74.61 \%$. The survey questions consisted of a total of 12 items ( 4 items for 1st factor: additional effort; 4 items for 2 nd factor: satisfied; and 4 items for 3 rd factor: trust). Cronbach a value, which is the reliability coefficient used in this study, was 0.899 for 'additional effort', 0.892 for 'satisfied', and 0.852 for 'trust'. The overall reliability was 0.944 , thereby suggesting that the questionnaire is reliable enough to be used in the survey.

\section{Questions on 'behavior after purchase'}

The questions on 'behavior after purchase' were prepared to suit the purpose of this study by revising and supplementing the questionnaire used by Park (2009) who adopted the questions used by Keller (1993). As shown in Table 5, the cumulative dispersion ratio (explanatory power) of the factor analysis on "behavior after purchase' was $83.55 \%$. The question items consisted of 4 items for 1st factor: recommend to others and 2 items for 2 nd factor: continue with exercise. Cronbach a value, which is the reliability coefficient used in this study, was 0.925 for 'recommend to others' and 0.815 for 'continue with exercise'. The overall reliability was 0.918 , suggesting that the questionnaire is reliable enough to be used in the survey.

\section{Investigation procedures and data processing Investigation procedure}

A preliminary investigation was conducted through a review of the previous literature and the first preliminary survey in this
Table 5. Factor analysis and reliability of the questions on 'behavior after purchase'

\begin{tabular}{lccc}
\hline Question & 1 & 2 & Shared value \\
\hline Recommend to others 1 & 0.900 & 0.240 & 0.867 \\
Recommend to others 2 & 0.844 & 0.377 & 0.855 \\
Recommend to others 3 & 0.810 & 0.388 & 0.807 \\
Recommend to others 4 & 0.769 & 0.415 & 0.764 \\
Continue with exercise 1 & 0.271 & 0.907 & 0.897 \\
Continue with exercise 2 & 0.469 & 0.777 & 0.823 \\
$\quad$ Total & 3.063 & 1.950 & \\
Dispersion (\%) & 51.045 & 32.507 & \\
Commutation (\%) & 51.045 & 83.551 & \\
Reliability & 0.925 & 0.815 & \\
Overall reliability & & 0.918 & \\
\hline
\end{tabular}

study before sending pre-educated researchers to visit the subject, distribute the questionnaire, and allow them to respond with a self-assessment instrument.

\section{Dataprocessing}

The data were analyzed through statistical analysis methods by using the IBM SPSS Statistics ver. 22.0 (IBM Co., Armonk, NY, USA).

First, the general characteristics of the samples were analyzed via frequency analysis, the validity of the questionnaire was verified through exploratory factor analysis, and the reliability was verified via Cronbach a test. Second, hypothesis testing was performed via correlation and regression analysis, and verified at a statistical significance level of $P<0.05$.

\section{RESULTS}

\section{Correlation analysis}

Table 6 shows the correlations between the related variables that are used in this study. Table 6 shows statistically significant relationships among the 36 correlation coefficients ( 34 at a significance level of $P<0.001$ and 2 at a significance level of $P<0.01$ ), except for the correlation coefficient among the self-variables.

\section{Effect of 'perceived body image' on the 'commitment' of Pilates consumers}

Table 7 shows that 'perceived body image' has a significant effect on 'commitment' at a significance level of $P<0.001$ ('appearance oriented' and 'satisfied'). The relative contribution to 'commitment' was found to be 'appearance oriented' $(\beta=0.297)$ and 'satisfied' ( $\beta=0.273)$, while the fit of the model testing result 
Table 6. Correlation analysis results among related variables

\begin{tabular}{|c|c|c|c|c|c|c|c|c|c|}
\hline & $A$ & B & C & $D$ & $E$ & $\mathrm{~F}$ & G & $\mathrm{H}$ & I \\
\hline$A$ & 1 & & & & & & & & \\
\hline$B$ & $0.378^{* * *}$ & 1 & & & & & & & \\
\hline$C$ & $0.717^{* * *}$ & $0.295^{* * *}$ & 1 & & & & & & \\
\hline$D$ & $0.518^{* * *}$ & $0.257^{* * *}$ & $0.506^{* * *}$ & 1 & & & & & \\
\hline$E$ & $0.279^{* * *}$ & $0.407^{* * *}$ & $0.274^{* * *}$ & $0.477^{* * *}$ & 1 & & & & \\
\hline$F$ & $0.282^{* * *}$ & $0.396^{* * *}$ & $0.202^{* *}$ & $0.378^{* * *}$ & $0.728^{* * *}$ & 1 & & & \\
\hline G & $0.238^{* * *}$ & $0.424^{* * *}$ & $0.201^{* *}$ & $0.390^{* * *}$ & $0.770^{* * *}$ & $0.783^{* * *}$ & 1 & & \\
\hline $\mathrm{H}$ & $0.350^{* * *}$ & $0.369^{* * *}$ & $0.340^{* * *}$ & $0.480^{* * *}$ & $0.632^{* * *}$ & $0.602^{* * *}$ & $0.605^{* * *}$ & 1 & \\
\hline I & $0.478^{* * *}$ & $0.302^{* * *}$ & $0.425^{* * *}$ & $0.611^{* * *}$ & $0.579 * * *$ & $0.520^{* * *}$ & $0.553^{* * *}$ & $0.716^{* * *}$ & 1 \\
\hline
\end{tabular}

A, appearance oriented; $B$, appearance judging; $C$, satisfied; $D$, commitment; $E$, additional effort; $F$, satisfied; $G$, trust; $H$, recommend to others; I, continue with exercise. ${ }^{* *} P<0.01 .{ }^{* *} P<0.001$.

Table 7. Regression analysis results of the effect of 'perceived body image' on 'commitment'

\begin{tabular}{|c|c|c|c|c|c|}
\hline \multirow{2}{*}{ Variable } & \multicolumn{2}{|c|}{ Nonstandardization } & \multirow{2}{*}{$\frac{\text { Standardization }}{\beta}$} & \multirow{2}{*}{$t$} & \\
\hline & B & SE & & & \\
\hline Constant & 1.937 & 0.267 & & 7.247 & $R^{2}=0.309$ \\
\hline $\begin{array}{c}\text { Appearance } \\
\text { oriented }\end{array}$ & 0.244 & 0.064 & 0.297 & $3.809^{* * *}$ & $\begin{array}{l}F=37.041 \\
P=0.000\end{array}$ \\
\hline $\begin{array}{l}\text { Appearance } \\
\text { judging }\end{array}$ & 0.073 & 0.065 & 0.064 & 1.123 & \\
\hline Satisfied & 0.243 & 0.067 & 0.273 & $3.614^{* * *}$ & \\
\hline
\end{tabular}

SE, standard error.

${ }^{* * *} P<0.001$.

shows that the determination coefficient $\left(R^{2}\right)$ is 0.309 , thereby confirming that the explanatory power of 'perceived body image' on 'commitment' is $30.9 \%$.

\section{Effect of 'perceived body image' on the 'attitude' of Pilates consumers}

\section{Effect of 'perceived body image' on the 'additional effort' of Pilates consumers}

Table 8 shows that 'appearance judging' of 'perceived body image' has a significant effect on 'additional effort' at $P<0.001$ level. The relative contribution to 'additional effort' was 'appearance judging' $(\beta=0.347)$, while the fit of the model testing result shows that the determination coefficient $\left(R^{2}\right)$ is 0.192 , thereby confirming that the explanatory power of 'perceived body image' on 'commitment' is $19.2 \%$.

\section{Effect of 'perceived body image' of the Pilates consumers on 'satisfied'}

Table 9 shows that 'appearance judging' of 'perceived body image' has a significant effect on 'satisfied' at $P<0.001$ level. The
Table 8. Regression analysis results of the effect of 'perceived body image' on 'additional effort'

\begin{tabular}{|c|c|c|c|c|c|}
\hline \multirow{2}{*}{ Variable } & \multicolumn{2}{|c|}{ Nonstandardization } & \multirow{2}{*}{$\frac{\text { Standardization }}{\beta}$} & \multirow{2}{*}{$t$} & \\
\hline & B & SE & & & \\
\hline Constant & 2.521 & 0.240 & & 10.525 & $R^{2}=0.192$ \\
\hline $\begin{array}{c}\text { Appearance } \\
\text { oriented }\end{array}$ & 0.035 & 0.057 & 0.051 & 0.606 & $\begin{array}{l}F=19.764 \\
P=0.000\end{array}$ \\
\hline $\begin{array}{l}\text { Appearance } \\
\text { judging }\end{array}$ & 0.327 & 0.058 & 0.347 & $5.645^{* * *}$ & \\
\hline Satisfied & 0.099 & 0.060 & 0.134 & 1.645 & \\
\hline
\end{tabular}

SE, standard error.

${ }^{* * *} P<0.001$.

Table 9. Regression analysis results of the effect of 'perceived body image' on 'satisfied'

\begin{tabular}{|c|c|c|c|c|c|}
\hline \multirow{2}{*}{ Variable } & \multicolumn{2}{|c|}{ Nonstandardization } & \multirow{2}{*}{$\frac{\text { Standardization }}{\beta}$} & \multirow{2}{*}{$t$} & \multirow{4}{*}{$\begin{array}{c}R^{2}=0.178 \\
F=17.935 \\
P=0.000\end{array}$} \\
\hline & B & SE & & & \\
\hline Constant & 2.866 & 0.229 & & 12.510 & \\
\hline $\begin{array}{l}\text { Appearance } \\
\text { oriented }\end{array}$ & 0.107 & 0.055 & 0.166 & 1.953 & \\
\hline $\begin{array}{l}\text { Appearance } \\
\text { judging }\end{array}$ & 0.302 & 0.055 & 0.339 & $5.451^{* * *}$ & \\
\hline Satisfied & -0.012 & 0.058 & -0.017 & -0.206 & \\
\hline
\end{tabular}

$\mathrm{SE}$, standard error.

${ }^{* * *} P<0.001$

relative contribution to 'satisfied' was found to be 'appearance judging' $(\beta=0.339$ ), while the fit of the model testing result shows that the determination coefficient $\left(R^{2}\right)$ is 0.178 , thereby confirming that the explanatory power of 'perceived body image' on 'satisfied' is $17.8 \%$.

\section{Effect of 'perceived body image' of the Pilates consumers on 'trust'}

Table 10 shows that 'appearance judging' of 'perceived body 
Table 10. Regression analysis results of the effect of 'perceived body image' on 'trust'

\begin{tabular}{|c|c|c|c|c|c|}
\hline \multirow{2}{*}{ Variable } & \multicolumn{2}{|c|}{ Nonstandardization } & \multirow{2}{*}{$\frac{\text { Standardization }}{\beta}$} & \multirow{2}{*}{$t$} & \\
\hline & B & SE & & & \\
\hline Constant & 2.758 & 0.223 & & 12.356 & \multirow{4}{*}{$\begin{aligned} R^{2} & =0.188 \\
F & =19.191 \\
P & =0.000 \\
* & \end{aligned}$} \\
\hline $\begin{array}{l}\text { Appearance } \\
\text { oriented }\end{array}$ & 0.038 & 0.053 & 0.061 & 0.716 & \\
\hline $\begin{array}{l}\text { Appearance } \\
\text { judging }\end{array}$ & 0.340 & 0.054 & 0.389 & $6.296^{* * *}$ & \\
\hline Satisfied & 0.029 & 0.056 & 0.042 & 0.518 & \\
\hline
\end{tabular}

$\mathrm{SE}$, standard error.

${ }^{* * *} P<0.001$

Table 11. Regression analysis results of the effect of 'perceived body image' on 'recommend to others' of 'behavior after purchase'

\begin{tabular}{|c|c|c|c|c|c|}
\hline \multirow{2}{*}{$\begin{array}{l}\text { Independent } \\
\text { Variable }\end{array}$} & \multicolumn{2}{|c|}{ Nonstandardization } & \multirow{2}{*}{$\frac{\text { Standardization }}{\beta}$} & \multirow{2}{*}{$t$} & \\
\hline & B & SE & & & \\
\hline Constant & 2.584 & 0.241 & & 10.741 & $R^{2}=0.202$ \\
\hline $\begin{array}{l}\text { Appearance } \\
\text { oriented }\end{array}$ & 0.087 & 0.058 & 0.126 & 1.507 & $\begin{array}{l}F=21.030 \\
P=0.000\end{array}$ \\
\hline $\begin{array}{l}\text { Appearance } \\
\text { judging }\end{array}$ & 0.258 & 0.058 & 0.272 & $4.440^{* * *}$ & \\
\hline Satisfied & 0.126 & 0.060 & 0.169 & $2.082^{*}$ & \\
\hline
\end{tabular}

$\mathrm{SE}$, standard error.

${ }^{*} P<0.05$. ${ }^{* *} P<0.001$.

image' has a significant effect on 'trust' at $P<0.001$ level. The relative contribution of 'trust' was found to be 'appearance judging' $(\beta=0.389)$, while the fit of the model testing result shows that the determination coefficient $\left(R^{2}\right)$ is 0.188 , thereby confirming that the explanatory power of 'perceived body image' on 'trust' is $18.8 \%$.

\section{Effect of'perceived body image' of the Pilates consumers on 'behavior after purchase'}

\section{Effect of 'perceived body image' of the Pilates consumers on 'recommend to others' of 'behavior after purchase'}

Table 11 shows that 'appearance judging' of 'perceived body image' has a significant effect on 'recommend to others' of 'behavior after purchase' at $P<0.001$ and 'satisfied' at the $P<0.05$ level, respectively. The relative contribution of 'behavior after purchase' to 'recommend to others' was found to be 'appearance judging' $(\beta=0.272)$ and 'satisfied' $(\beta=0.169)$, while the fit of the model testing result shows that the determination coefficient $\left(R^{2}\right)$ is 0.202 , thereby confirming that the explanatory power of 'perceived body image' on 'recommend to others' of 'behavior after purchase' is $20.2 \%$.
Table 12. Regression analysis results of the effect of 'perceived body image' on 'continue with exercise' of 'behavior after purchase'

\begin{tabular}{|c|c|c|c|c|c|}
\hline \multirow{2}{*}{ Variable } & \multicolumn{2}{|c|}{ Nonstandardization } & \multirow{2}{*}{$\frac{\text { Standardization }}{\beta}$} & \multirow{2}{*}{$t$} & \\
\hline & B & SE & & & \\
\hline Constant & 2.062 & 0.286 & & 7.221 & $R^{2}=0.259$ \\
\hline $\begin{array}{c}\text { Appearance } \\
\text { oriented }\end{array}$ & 0.262 & 0.068 & 0.309 & $3.826^{* * *}$ & $\begin{array}{l}F=28.978 \\
P=0.000\end{array}$ \\
\hline $\begin{array}{l}\text { Appearance } \\
\text { judging }\end{array}$ & 0.161 & 0.069 & 0.137 & $2.331^{*}$ & \\
\hline Satisfied & 0.149 & 0.072 & 0.163 & $2.081^{*}$ & \\
\hline
\end{tabular}

$\mathrm{SE}$, standard error.

${ }^{*} P<0.05 .{ }^{* * *} P<0.001$.

Table 13. Regression analysis result of the effect of 'commitment' on 'additional effort'

\begin{tabular}{|c|c|c|c|c|c|}
\hline \multirow{2}{*}{ Variable } & \multicolumn{2}{|c|}{ Nonstandardization } & \multirow{2}{*}{$\frac{\text { Standardization }}{\beta}$} & \multirow{2}{*}{$t$} & \\
\hline & B & SE & & & \\
\hline Constant & 2.757 & 0.187 & & 14.762 & $R^{2}=0.227$ \\
\hline Commitment & 0.395 & 0.046 & 0.477 & $8.595^{* * *}$ & $\begin{array}{l}F=73.878 \\
P=0.000\end{array}$ \\
\hline
\end{tabular}

SE, standard error.

${ }^{* * *} P<0.001$

\section{Effect of 'perceived body image' of the Pilates consumers on 'continue with exercise' of 'behavior after purchase'}

Table 12 shows that 'appearance oriented' of 'perceived body image' has a significant effect on 'continue with exercise' of 'behavior after purchase' at $P<0.001$, and 'appearance judging' and 'satisfied' at $P<0.05$ level, respectively. The relative contribution of 'behavior after purchase' to 'continue with exercise' was 'appearance oriented' ( $\beta=0.309)$, 'appearance judging' $(\beta=0.137)$, and 'satisfied' $(\beta=0.163)$, while the fit of the model testing result shows that the determination coefficient $\left(R^{2}\right)$ is 0.259 , thereby confirming that the explanatory power of 'perceived body image' on 'continue with exercise' is $25.9 \%$.

\section{Effect of 'commitment' on the 'attitude' of Pilates consumers}

\section{Effect of 'commitment' of the Pilates consumers on 'additional effort'}

Table 13 shows that 'commitment' has a significant effect on 'additional effort' at $P<0.001$ level. The relative contribution of 'attitude' toward 'additional effort' was found to be 'commitment' $(\beta=0.477)$, while the fit of the model testing result shows that the determination coefficient $\left(R^{2}\right)$ is 0.227 , thereby confirming that the explanatory power of 'commitment' on 'additional effort' is $22.7 \%$. 
Table 14. Regression analysis result of the effect of 'commitment' on 'satisfied'

\begin{tabular}{|c|c|c|c|c|c|}
\hline \multirow{2}{*}{ Variable } & \multicolumn{2}{|c|}{ Nonstandardization } & \multirow{2}{*}{$\frac{\text { Standardization }}{\beta}$} & \multirow{2}{*}{$t$} & \\
\hline & $B$ & SE & & & \\
\hline Constant & 3.239 & 0.186 & & 17.378 & $R^{2}=0.143$ \\
\hline Commitment & 0.297 & 0.046 & 0.378 & $6.478^{* * *}$ & $\begin{array}{l}F=41.960 \\
P=0.000\end{array}$ \\
\hline
\end{tabular}

SE, standard error.

${ }^{* * *} P<0.001$.

Table 15. Regression analysis result of the effect of 'commitment' on 'trust'

\begin{tabular}{|c|c|c|c|c|c|}
\hline \multirow{2}{*}{ Variable } & \multicolumn{2}{|c|}{ Nonstandardization } & \multirow{2}{*}{$\frac{\text { Standardization }}{\beta}$} & \multirow{2}{*}{$t$} & \\
\hline & B & SE & & & \\
\hline Constant & 3.179 & 0.182 & & 17.490 & $R^{2}=0.152$ \\
\hline Commitment & 0.301 & 0.045 & 0.390 & $6.711^{* * *}$ & $\begin{array}{l}F=45.036 \\
P=0.000\end{array}$ \\
\hline
\end{tabular}

SE, standard error.

${ }^{* * *} P<0.001$

\section{Effect of 'commitment' of the Pilates consumers on 'satisfied'}

Table 14 shows that 'commitment' has a significant effect on 'satisfied' at $P<0.001$ level. The relative contribution toward 'satisfied' was found to be 'commitment' $(\beta=0.378)$, while the fit of the model testing result shows that the determination coefficient $\left(R^{2}\right)$ is 0.143 , thereby confirming that the explanatory power of 'commitment' on 'satisfied' is $14.3 \%$.

\section{Effect of 'commitment' of the Pilates consumers on 'trust'}

Table 15 shows that 'commitment' has a significant effect on 'trust' at $P<0.001$ level. The relative contribution to 'trust' was positively correlated with 'commitment' $(\beta=0.390)$, while the fit of the model testing result shows that the determination coefficient $\left(R^{2}\right)$ is 0.152 , thereby confirming that the explanatory power of 'commitment' on 'Trust' is $15.2 \%$.

\section{Effect of 'commitment' of the Pilates consumers on 'behavior after purchase'}

\section{Effect of 'commitment' of the Pilates consumers on 'recommend to others' of 'behavior after purchase'}

Table 16 shows that 'commitment' has a significant effect on 'recommend to others' of 'behavior after purchase' at $P<0.001$ level. The relative contribution of 'behavior after purchase' to 'recommend to others' was 'commitment' $(\beta=0.480)$, while the fit of the model testing result shows that the determination coefficient $\left(R^{2}\right)$ is 0.230 , thereby confirming that the explanatory power of 'commitment' on 'recommend to others' of 'behavior after purchase' is $23.0 \%$.
Table 16. Regression analysis result of the effect of 'commitment' on 'recommend to others' of 'behavior after purchase'

\begin{tabular}{|c|c|c|c|c|c|}
\hline \multirow{2}{*}{ Variable } & \multicolumn{2}{|c|}{ Nonstandardization } & \multirow{2}{*}{$\frac{\text { Standardization }}{\beta}$} & \multirow{2}{*}{$t$} & \\
\hline & $B$ & SE & & & \\
\hline Constant & 2.798 & 0.188 & & 14.853 & $R^{2}=0.230$ \\
\hline Commitment & 0.402 & 0.046 & 0.480 & $8.667^{* * *}$ & $\begin{array}{l}F=75.111 \\
P=0.000\end{array}$ \\
\hline
\end{tabular}

SE, standard error.

${ }^{* * *} P<0.001$.

Table 17. Regression analysis result of the effect of 'commitment' on 'continue with exercise' of 'behavior after purchase'

\begin{tabular}{|c|c|c|c|c|c|}
\hline \multirow{2}{*}{ Variable } & \multicolumn{2}{|c|}{ Nonstandardization } & \multirow{2}{*}{$\frac{\text { Standardization }}{\beta}$} & \multirow{2}{*}{$t$} & \\
\hline & B & SE & & & \\
\hline Constant & 1.674 & 0.209 & & 8.002 & $R^{2}=0.374$ \\
\hline Commitment & 0.631 & 0.052 & 0.611 & $12.240^{* * *}$ & $\begin{array}{l}F=149.809 \\
P=0.000\end{array}$ \\
\hline
\end{tabular}

SE, standard error.

${ }^{* * *} P<0.001$.

\section{Effect of 'commitment' of the Pilates consumers on 'continue with exercise' of 'behavior after purchase'}

Table 17 shows that 'commitment' has a significant effect on 'continue with exercise' of 'behavior after purchase' at $P<0.001$ level. The relative contribution of 'behavior after purchase' to 'continue with exercise' was found to be 'commitment' $(\beta=$ 0.611 ), while the fit of the model testing result shows that the determination coefficient $\left(R^{2}\right)$ is 0.374 , thereby confirming that the explanatory power of 'commitment' on 'continue with exercise' of 'behavior after purchase' is $37.4 \%$.

\section{DISCUSSION}

As a result of the growing social interest in wellbeing, beautiful appearance and slender body shape are both being envied by the young and old alike regardless of their gender, and people are paying more attention to their perceived body image. Due to the influence of this shifting environment, an increasing number of people are learning Pilates as it helps them maintain their overall physical and mental health (Hong et al., 2014). Based on the results of this study on the relationship between 'perceived body image' and 'commitment' of the Pilates consumers and 'behavior after purchase', the author intends to suggest some methods that would increase the commitment to exercise, form a positive attitude, and increase the behavior after purchase.

First, the analysis of 'perceived body image' and 'commitment' of the Pilates consumers shows that 'perceived body image' has a 
significant effect on the 'appearance oriented' and 'satisfied' attitudes, thereby suggesting that Pilates induces physical commitment by raising a person's interest on the appearance of the body, increasing their satisfaction on their perceived body image, and improving their concentration on body movement (Lee, 2013). This is because Pilates requires participants to integrate their mind and body, help correct bad posture, strengthen the muscles, and enhance flexibility to maintain the balance of the body, thereby enhancing the perceived body image positively.

In this regard, this study is supported by the research of Kim et al. (2013), who concluded that dance sport athletes can achieve a positive performance when they have a positive view on their perceived body image, and that they can improve their confidence and commitment to their performances as their skills and athletic abilities improve (Kim, 2006).

Therefore, it is necessary to apply the program that takes into account the physical ability and the characteristics that are effective for mental concentration by employing systemized muscle strengthening programs in order to develop well-balanced muscles for the learners of Pilates with maximum effect. This way, it would be possible to increase the subjective evaluation of the body, thereby providing fun and enjoyment to learners and increasing their commitment to exercise.

Second, the analysis of the 'perceived body image' and 'attitude' of the Pilates consumers shows that the 'appearance judging' of the 'perceived body image' has a significant effect on the 'additional effort', 'satisfied', and 'trust' attitudes, thereby suggesting that Pilates provides a variety of information on the identity, values, mood, and social position of Pilates consumers. It also satisfies the physiological, psychological, and social needs and values of the participants with regard to 'appearance judging' attitude, which is considered as a key attribute in social life, thereby forming a positive attitude and enhancing the quality of life by providing pleasure and opportunity to live a happy life (Lee, 2000).

In this regard, satisfactory subjective evaluation of the body allows people to enjoy self-confidence, psychological stability, and satisfaction with their body (Lee and Jang, 2013). Roh (2015) also showed that Pilates consumers can form the 'trust' attitude by maintaining a harmonious balance between external physical development and internal body functions. In addition, positive perception and body image assessment fosters positive beliefs, changes in values, physical health, and attitude toward life, thereby supporting the results of this study.

Therefore, the most important feature of Pilates is that it allows participants to have a flexible and balanced body, achieve good posture, and soften their body while strengthening their muscles. In addition to the application of the programs based on the six basic principles of breathing, centralization, control, accuracy, concentration, and flow, professional guidance is required to instill positive perceptions of their appearance.

Third, an analysis of the effect of the 'perceived body image' of the Pilates consumers on their 'behavior after purchase' shows that 'appearance judging' and 'satisfied' have significant effects on 'recommend to others' and 'appearance oriented' attitudes of 'behavior after purchase', whereas the 'appearance judging' and 'satisfied' attitudes have significant effects on the 'continue with exercise' attitude of 'behavior after purchase.' These results suggest that the participants recognize their body structure, they are aware of their ideal body, they pay attention to the correct posture, and they pursue both physical beauty and inner beauty by learning Pilates (Park, 2009), thereby prompting them to experience positive changes in their perceived body images and to recommend others to participate in the exercise.

Nam et al. (2009) have also proven that people are more likely to actively purchase body-related goods in order to compensate for any unsatisfactory physical conditions if there is a significant gap between the actual body condition and the ideal body condition, thereby supporting the results that people are more likely to purchase body-related goods when they have a positively perceived body image.

Therefore, the Pilates consumers are believed to continue their exercise when systematic exercise methods for their physical changes are delivered, and when their interest is heightened by the application of programs based on their interest and desire. As a result, they would continue to exercise through continuous participation and recommendation to others.

Fourth, the analysis of the relationship between 'commitment' and the attitude of the pilates consumers shows that 'commitment' had a significant effect on the 'additional effort', 'satisfied', and 'trust' attitudes, thereby suggesting that the Pilates consumers engage in additional effort since the Pilates is a movement that requires the union of mind and body, and when people become focused on commitment, they also become more focused on their workout, happiness, and satisfaction (Lee and Park, 2016).

Decotiis and Summers (1987) demonstrated that there is a relationship between the 'additional effort' for performance improvement and 'trust' attitude, thereby supporting the results of this study. Therefore, it is possible to create a positive attitude among the Pilates consumers by promoting an indoor environment where the Pilates consumer can commit to the exercise, such as a com- 
fortable facility, proper lighting for concentration, and matching background music, and by designing a program structure for the perfect commitment to the exercise.

Fifth, the analysis of the relationship between 'commitment' and 'behavior after purchase' of the Pilates consumers shows that 'commitment' has a significant effect on 'recommend to others' and 'continue with exercise' of 'behavior after purchase', thereby suggesting that Pilates enhances the sense of accomplishment and confidence in exercise participation by helping the participants to concentrate on their body movement and by prompting physical commitment (Lee, 2013), thereby allowing them to participate continuously in the exercise and to recommend it to others.

In this regard, Lee (2013) showed that a high level of commitment is related to improved exercise performance and high participation rate, while Son and Hong (2008) demonstrated that the more committed the participants are in the activities, the more likely they are to recommend this to others, thereby supporting the results of this study.

Therefore, the Pilates consumers are expected to promote continuous exercise and deliver positive images on Pilates by expressing their interest in the exercise effect and posture corrections as a result of their commitment to the exercise.

\section{CONFLICT OF INTEREST}

No potential conflict of interest relevant to this article was reported.

\section{REFERENCES}

An JJ, Jeon MR. The relationship between perceived body image of dance students and satisfactory body management and dance performance. Korean Dance J 2014;14:35-44.

Bass BM. Leadership and performance beyond expectations. New York: Free Press; 1985.

Cash TF, Pruzinsky T. Body images: development, deviance, and change. New York: Guilford Press; 1990.

Decotiis TA, Summers TP. A path analysis of a model of the antecedents and consequences of organizational commitment. Human Relat 1987; 40:445-470.

Hong SY, Park HA, Won HJ. Pilates leaders' exercise experience stages and changes in life expectancy. J Korean Phys Soc 2014;22:173-187.

Kanungo RN. Measurement of job and work involvement. J Appl Psychol 1982;67:341-349.

Keller KL. Conceptualizing, measuring, managing customer-based equi- ty. J Mark 1993;57:1-22.

Kim JY, Yoon AY, Ju HC. A structural relationship between perceived body image, self-efficacy and dance commitment of dance sports players. J Coach Abil Dev 2013;15:107-117.

Kim SG. A study on the relationship between exercise commitment, psychological well-being and exercise addition. Korea Sport Res 2006;17: 451-460.

Lee $\mathrm{CH}$. The structural relationship between intention to participate in Taekwondo training and commitment to exercise, and recommend to others intention. J Korean Phys Educ 2014;23:701-713.

Lee JM, Jang HS. A study on the body image and sense of psychological stability related to the outward appearance management. J Korean Soc Cosmetol 2013;19:1174-1185.

Lee JY. The effect of commitment experience on organizational citizenship behavior and floor organizational behavior. J Korean Phys Educ Assoc 2000;39:161-174.

Lee JY. The effects of Pilates participation on exercise commitment and exercise performance in female golfers. Korean Dance J 2013;13:1-8.

Lee TY, Park MS. Pilates' perceived leadership expertise is related to exercise commitment and customer satisfied. J Korean Phys Educ 2016;25: 667-678.

Nam SJ, Lee EH, Hwang YS. The perceived body image of adolescent consumers and clothing purchase behavior model according to selfesteem: focused on the effect of perceived mass media commitment and perceived difference in physical condition. Consum Cult Res 2009; 12:123-146.

Park EA, Sung YS. The effect of consumer perceptions on purchase intention on announcement model: focused on perceived body image comparison. Korean J Psychol 2011;2:87-116.

Park MH. Change of body through experience of Pilates mat course. J Korean Phys Soc 2009;17:273-285.

Prime Economy. Pilates of Roh, Su-Yeon. Prime Economy. 2017 Sep 28. Available from: http://www.newsprime.com/news/article.html?$\mathrm{No}=390235$.

Roh SY. The relationship between the objectified body consciousness of self-control and perfectionism attitude of Pilates participants. J Korean Socy Sport Sci 2015;13:225-237.

Roh SY. The relationship between physical self-concept and psychological well-being and subjective well - being of Pilates participants. J Korean Phys Educ Assoc 2016;55:207-219.

Smoll FL, Smith RE, Curtis B, Hunt E. Toward a mediational model of coach-player relationships. Res Q 1978;49:528-541.

Son SB, Hong SP. The relationships among perceived ability, flow experience and post-purchasing behavior of sports club members. Korean J Phys Educ 2008;47:217-226. 
Song EI, Lee JH. The effect of college Taekwondo players' self-management on sport confidence, exercise commitment, and exercise Satisfaction. J Korea Wellness Soc 2015;10:171-182.

Sonstroem RJ, Morgan WP. Exercise and self-esteem: rationale and mod- el. Med Sci Sports Exerc 1989;21:329-337.

Wassner A. The impact of mutilating surgery or trauma on body-image. Int Nurs Rev 1982;29:86-90. 